\title{
Evidence on the prevalence, incidence, mortality and trends of human papilloma virus-associated cancers in sub-Saharan Africa: systematic scoping review
}

\author{
Kabelo M. B. Lekoane ${ }^{1}$, Desmond Kuupiel ${ }^{1,2^{*}}$, Tivani P. Mashamba-Thompson ${ }^{1}$ and Themba G. Ginindza ${ }^{1}$
}

\begin{abstract}
Background: Human papilloma virus (HPV) associated cervical cancer remains a global concern particular, in SubSaharan Africa (SSA) where the impact is felt most. Evidence show that many other cancers such as vaginal, anal, oropharyngeal, penile are because of persistent infection with HPV especially, high-risk types.

Aim: We mapped evidence on the incidence, prevalence, mortality, and the trends of human papillomavirus-related cancers in SSA.

Methods: A comprehensive literature search was conducted from several databases including PubMed, Google scholar, Science Direct, and CINAHL and MEDLINE via EBSCOhost as well as World Health Organization website for grey literature. Studies reporting HPV-related cancers in SSA outcomes including prevalence, incidence, mortality, and trends were included in this study. The risk of bias of the included studies were assessed using the mixed methods appraisal tool version 2011. We employed PRISMA (preferred reporting items for systematic reviews and meta-analyses) to report the search results. Thematic analysis used to reveal the emerging themes from the included studies.

Results: Seventy-four (74) studies were retrieved at full article screening, eight of them (six reviews, and two quantitative study) were eligible for data extraction. The degree of agreement between the two independent reviewers following full article screening, was $86.49 \%$ agreement versus $64.57 \%$ likely by chance which constituted moderate to significant agreement (Kappa statistic $=0.62$, $p$-value $<0.05$ ). Of the eight included studies, four (50\%) studies generalized about SSA with no country of interest; two (25\%) studies were conducted in Nigeria; one (12.5\%) reported about Uganda, Zambia, Guinea, Malawi Tanzania, Mali, Mozambique, Zimbabwe; and one (12.5\%) reported about Ethiopia, Senegal, Zimbabwe and Uganda. These eight included studies reported evidence on more than one outcome of interest. Four studies reported about the prevalence of HPV-related cancers, seven studies reported about the incidence, four studies reported about mortality, and four studies reported about the trends of HPV-related cancers.

\footnotetext{
* Correspondence: desmondkuupiel98@hotmail.com

${ }^{1}$ Discipline of Public Health Medicine, School of Nursing and Public Health, University of KwaZulu-Natal, 2nd Floor George Campbell Building, Howard College Campus, Durban 4001, South Africa

${ }^{2}$ Research for Sustainable Development, Sunyani, Ghana
}

(c) The Author(s). 2019 Open Access This article is distributed under the terms of the Creative Commons Attribution 4.0 International License (http://creativecommons.org/licenses/by/4.0/), which permits unrestricted use, distribution, and reproduction in any medium, provided you give appropriate credit to the original author(s) and the source, provide a link to the Creative Commons license, and indicate if changes were made. The Creative Commons Public Domain Dedication waiver (http://creativecommons.org/publicdomain/zero/1.0/) applies to the data made available in this article, unless otherwise stated. 


\begin{abstract}
(Continued from previous page)
Conclusion: This study observation highlighted a gap of knowledge regarding the epidemiological data on the recent HPV prevalence in SSA, which will have a potential impact in determining the distribution of HPV on different body sites (cervix, penis, vagina, vulva, anus and oropharynx). Ongoing research projects are recommended in SSA to enhance the value of HPV, and HPV-associated cancers epidemiological data to inform strategies or/and policies on prevention, diagnosis, and treatment of HPV-related conditions.
\end{abstract}

Keywords: Human papilloma virus, Human papilloma virus -related cancer, Incidence, Prevalence, Mortality, Trends, SSA

\section{Background}

Human Papilloma Virus (HPV) is a small non-enclosed deoxyribonucleic acid virus that mostly infect the cells of the epithelium [1]. Human papilloma virus is known as one of the common causes of sexually transmitted infections (STI's) worldwide [2]. Globally, more than 170 HPV genotypes have been identified so far [3], and 15 of them $(16,18,31,33,35,39,45,51,52,56,58,59,68,73$, and 82 ) are highly recognized as high-risk HPV types (hr-HPV) and are intricate in HPV-related cancers development [4, 5]. HPV strains 16 and 18 are highly prevalent in Africa and they are noted to be the major cause of over $65 \%$ cervical cancer cases in the SSA [6, 7]. Over $95 \%$ of cervical cancers are said to be associated with hr-HPV infection, as well as about $75-90 \%$ anal cancers and a significant percentage of vaginal, penile, vulvar cancers, and oropharyngeal [8].

Globally, over $4 \%$ of all types of cancer cases, almost $2 \%$ of cancers in high-income countries (HICs), and nearly $8 \%$ in low-income countries (LICs) are attributable to hr-HPV [9]. The highest prevalence of cervical HPV infection is reported in Sub-Saharan Africa (SSA), with Guinea (48\%) and Mozambique (41\%) been the most report [10, 11]. According to World Health Organization (WHO), by 2030 cervical cancer will be responsible for 443,000 deaths of women worldwide [12]. Ninety-eight percentage of the predicted deaths will occur in LICs, with SSA having the highest number of deaths [11]. Body of evidence on HPV-related anogenital cancers is increasing, according to de Martel $\mathrm{C}$ et al., worldwide estimation of new cases yearly for vaginal cancer is $13,000,27,000$ for vulvar cancer and 27,000 for anal cancer respectively [13]. Penile cancer incidence rates are higher in LICs than in HICs. It is estimated that penile cancers account for about 22,000 (9.5\%) cancer cases worldwide in Africa, South America, and Asia [14].

However, progress has been made to prevent the HPV infection through development of the three FDA approved HPV vaccines; Gardasil ${ }^{\circ}$, Gardasil $^{\circ}$ 9, and Cervarix $^{\circ}$ and they protect against HPV disease causing types $[15,16]$. These vaccines provide protection in women aged 9-26 years against HPV 6, 11, 16 and 18- associated cervical cancer, and others such as anogenital cancers (vaginal and vulvar), adenocarcinoma in situ, cervical intraepithelial neoplasia (CIN), vulvar intraepithelial neoplasia and vaginal intraepithelial neoplasia and genital warts [17]. The bivalent vaccine also provide protection in women aged 10-25 years against HPV 16 and 18- associated cervical cancer, adenocarcinoma in situ and CIN grades 1 [18]. We therefore, aimed to map evidence on the incidence, prevalence, mortality as well as trends of HPV-related cancers in SSA. It is envisaged that the findings of this study will, help to strengthen the implementation of preventative strategies and improve the preventive and control and treatment, programs to reduce the burden and mortality of HPVrelated cancers in SSA. It is also anticipated that the results of this study will benefit public health research by identifying gaps on current studies for future research.

\section{Methods}

This study forms part of the larger study titled; "Mapping evidence on the distribution of Human Papillomavirus-related cancers in sub-Saharan Africa: scoping review". This study is registered in PROSPERO under registration number CRD42017062403. A thorough description of the methods used in this study can be found in the published protocol [19].

\section{Search strategy}

We conducted a thorough literature search in the following databases: PubMed, Science Direct, Google scholar, and CINAHL and MEDLINE with full text via EBSCOhost platform for published studies. We also search WHO website for grey literature. The database search occurred from March 2017 to July 2017. Titles of the eligible studies were searched by using the following keywords combination in the databases "HPV-related cancers", "prevalence", "incidence", "mortality", "trends", and "Sub-Saharan Africa". Keywords during the search were separated by the usage of Boolean terms AND/OR. Language and date restrictions were not applied on the search. There was inclusion of Medical Subjects 
Headings $(\mathrm{MeSH})$ terms in the search. Additional eligible articles identified by reviewing reference sections of articles.

\section{Eligibility criteria \\ Inclusion criteria}

- Evidence of study conducted in Sub-Saharan Africa

- Study that included individuals with HPV-related cancers

- Evidence that focus on prevalence, incidence, mortality and trends of HPV-related cancers

\section{Exclusion criteria}

- Studies that do not focus on HPV-related cancers

- Studies not focusing on humans

- Qualitative studies were excluded

Firstly, one reviewer searched for the titles of the eligible studies from the databases based on the eligibility criteria. Duplicates studies were removed. Secondly, two reviewers screened all retrieved abstracts and they were evaluated for eligibility using the inclusion criteria. Studies that included humans' beings and reported at least one outcome of this study were selected. Where the reviewer was uncertain with the eligibility of study population, intervention, outcome and study setting were eligible the article was included in the next stage for screening. Agreement between the reviewers about potentially relevant studies was reached by consent and the full text obtained for screening. Thirdly, full article screening was done by two independent reviewers and a third investigator engaged to address disagreements between reviewers. We used Cohen's kappa coefficient $(\mathrm{K})$ statistic in Stata version 13 to calculate degree of agreement between reviewers.

\section{Charting data}

Data from the included studies was extracted using a formulated data form. For all studies, information on the author and date, study setting, outcome (prevalence, incidence, mortality and trends), age, percentage of males/ females, gender, study designs were extracted.

\section{Summary and collating}

Thematic analysis was performed to show evidence on the prevalence, incidence, mortality as well as the HPVassociated cancer trends in SSA from the included studies. The results from the included studies were summarised and manually coded and categories or themes as follows:

- Prevalence
- Incidence

- Mortality

- Trends

\section{Quality assessment}

The mixed methods appraisal tool version 2011 was used to assess the methodological quality of the included studies [21]. Of the eight included studies, two of them were assessed to determine their quality. Two reviewers independently performed the quality assessment and the results were communicated. The following domains were used to score the risk of bias of the included studies: research questions clarity, the research question confidence assessment, suitability of the data sources collected; statistical analysis appropriateness to address the research question. Additional domains included are as follows: the design and allocated concealment clearly described, complete data outcome and the withdrawal, recruiting of participants, the suitability of measurements and comparable participants, applicable sample and representative of the population, applicable design and mixing of methods and researchers' suitably considered method. An overall quality score percentage of the included studies was calculated, and scores interpreted as $\leq 50 \%$ low quality, $51-75 \%$ average quality, and $76-$ $100 \%$ high quality. The included studies overall quality percentage score was calculated, and scores were interpreted as high quality (100\%).

\section{Results}

We obtained 25,835 articles from all databases during the initial search. About 306 articles qualified for abstract screening, after exclusion of duplicates about 194 different articles remained. Of those, about 73 articles were recognized for full article screening. Based on the review of the full article screening, 65 articles were excluded in this study. Then eight articles were deemed qualified for inclusion in data withdrawal. Applying our inclusion criteria, the number remained at eight (Fig. 1).

Following full article screening, there was $86.49 \%$ agreement versus $64.57 \%$ expected by chance between the two independent reviewers which constituted of moderate to substantial consensus (Cohen's kappa = 0.62 , calculated probability of $<0.05$ ). In addition, the chi-square statistic by McNemar's implies that ratios of yes/no by reviewer is not a statistically significant difference with $p$-value $>0.05$.

From the eligible 194 studies considered for screening, an overall of 121 studies were unable to meet the eligible criteria and were deemed unsuitable for this study. Meanwhile, a sum total of 73 studies were selected for full article screening, 65 of them did not have important 


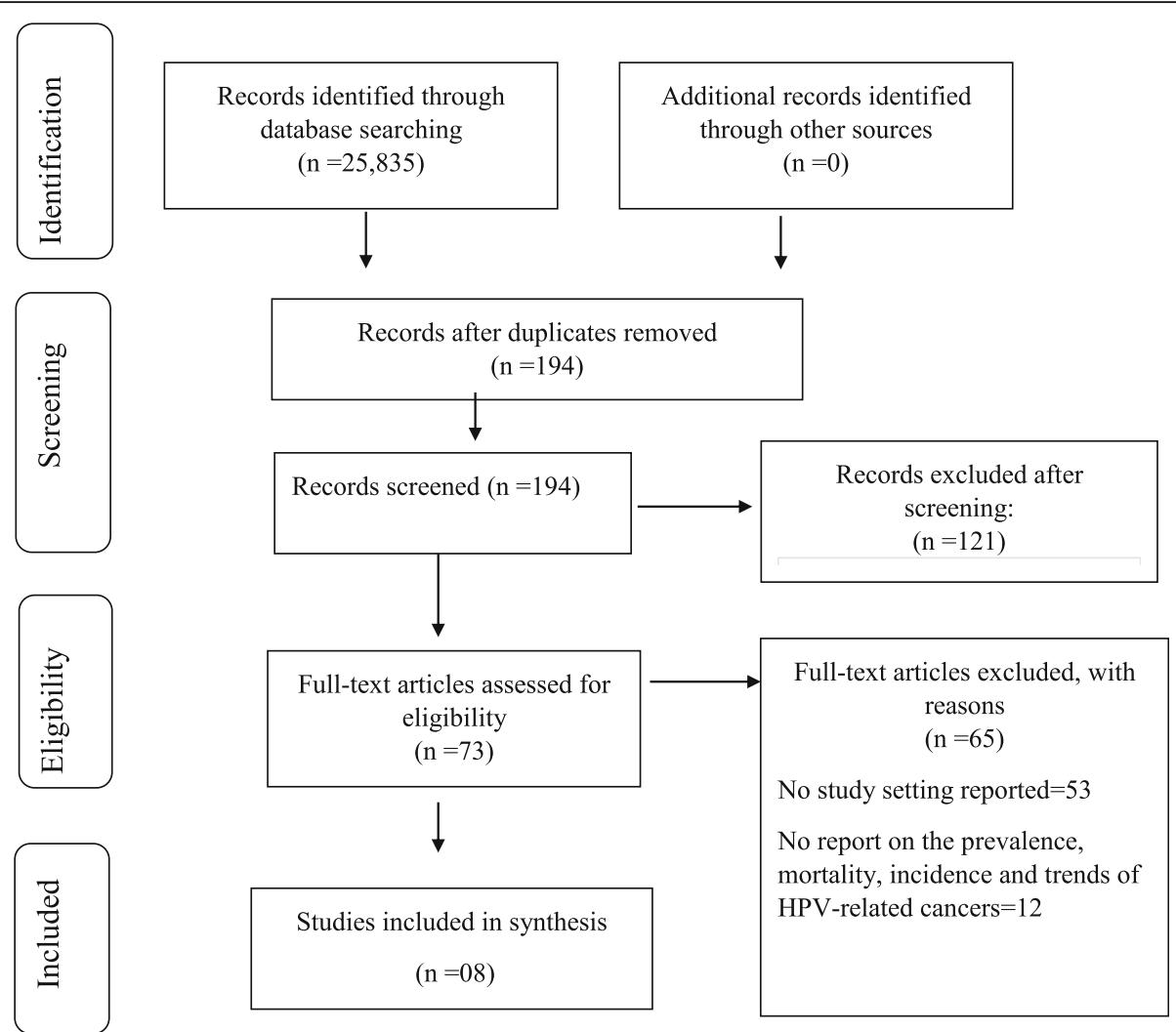

Fig. 1 PRISMA chart showing literature search and selection of studies

data to be used in this study. A total number of 53 articles did not report evidence on the study setting of interest which is SSA [22-74] and 12 did not report anything about the prevalence, incidence, mortality, and trends of HPV-related cancers [75-86].

\section{The elements of the included studies}

Included studies elements are presented on Table 1 . We included research work that focused on individuals with HPV-linked cancers, conducted within SSA focusing on the prevalence, incidence, mortality and

Table 1 Elements of the included studies

\begin{tabular}{|c|c|c|c|c|c|c|}
\hline \multirow[t]{2}{*}{ Author and date } & \multicolumn{3}{|c|}{ Study population } & \multirow[t]{2}{*}{ Study setting } & \multirow[t]{2}{*}{ Study design } & \multirow[t]{2}{*}{ Outcome reported } \\
\hline & $\begin{array}{l}\text { gender and } \\
\text { age }\end{array}$ & $\begin{array}{l}\text { number or } \\
\text { population } \\
\text { percentage }\end{array}$ & type & & & \\
\hline Louie et al., 2009 [90] & Men, women & Not specified & Not specified & $\begin{array}{l}\text { Sub-Saharan Africa (SSA), } \\
\text { Zimbabwe, Uganda, } \\
\text { Ethiopia Senegal }\end{array}$ & Review & Prevalence, incidence \\
\hline De Vuyst et al., 2013 [10] & Women & Not specified & Not specified & $\begin{array}{l}\text { SSA, Guinea, Zambia, } \\
\text { Tanzania, Malawi, } \\
\text { Mozambique, Zimbabwe, } \\
\text { Uganda, Mali }\end{array}$ & Review & $\begin{array}{l}\text { Prevalence, incidence, } \\
\text { trends }\end{array}$ \\
\hline Bosch et al., 2013 [87] & Women & Not specified & Not specified & SSA & Review & $\begin{array}{l}\text { Prevalence, incidence, } \\
\text { mortality, trends }\end{array}$ \\
\hline Arbyn et al.,2011 [88] & Women & Not specified & Not specified & SSA & Review & Incidence, mortality \\
\hline Forman et al., 2012 [91] & Women & Not specified & Not specified & SSA & Review & Incidence, mortality \\
\hline Jedy et al.,2016 [92] & Men, women & Not specified & Not specified & Nigeria & $\begin{array}{l}\text { Descriptive cross- } \\
\text { sectional study }\end{array}$ & $\begin{array}{l}\text { Prevalence, incidence, } \\
\text { trends }\end{array}$ \\
\hline Oga et al., 2016 [93] & Men, Women & Not specified & Not specified & Nigeria & Retrospective study & Prevalence \\
\hline De Sanjose et al., 2014 [89] & Women & Not specified & Not specified & SSA & Review & Incidence, trends \\
\hline
\end{tabular}


trends of cancers linked to HPV. The studies comprised of $75 \%(6 / 8)$ of review articles [10, 87-91], and $25 \%(2 / 8)$ of quantitative study [92, 93].

These studies were conducted and reviewed in different study setting, approximately $50 \%$ (4/8) studies generalized about SSA, with no country of interest [87-89, 91], 25\% (2/8) study was conducted in Nigeria [92, 93], and one (1/8) multi-country study reported about Uganda, Zambia, Guinea, Malawi Tanzania, Mali, Mozambique, Zimbabwe [10]. Another one (1/8) multicountry study was also reported about Ethiopia, Senegal, Zimbabwe and Uganda [90]. It was not mentioned in all the studies whether they were conducted in urban or rural setting. Of the included studies, $62.5 \%(5 / 8)$ studies reported about women $[10,87-89,91]$, and $37.5 \%(3 / 8)$ reported about both men and women $[90,92,93]$ as illustrated in Fig. 2.

From the eight included studies, four studies reported about HPV-related cancers prevalence [87, 90, 92, 93], seven studies reported about the incidence [10, 87-92], three studies reported about mortality [10, 87, 91], and four studies reported about HPV-related cancers trends $[10,87,89,92]$. Age of the population and the sample size of participants were not mentioned in the included studies.

The Mixed Methods Appraisal Tool (MMAT) Version 2011 was used to assess the methodological quality of two primary studies, from the eight included studies [27]. The studies scored $100 \%$ [92, 93] and were considered to be of high methodological quality. The evidence showed overall minimal risk of bias.

\section{Study findings}

The following subtopics were presented to analyse the data from the included studies: prevalence; incidence; mortality; and trends of cancers linked to HPV.

\section{Prevalence}

Out of the eight included studies, four studies reported on the prevalence cancers associated with HPV infection [87, 90, 92, 93]. Amongst women with normal cytology in SSA, it's been found that HPV infection prevalence is topmost at $24 \%$ as compared to worldwide prevalence of around $11-12 \%$ [87]. The overall estimated widespread presence of HPV 16/18 infection linked to invasive cervical cancer (ICC) cases in SSA is $69.2 \%$ which is coherent with the estimation of 70\% worldwide [90]. HPV 16 and 18 prevalence in ICC cases were found to be $43.7 \%$ in Senegal and 90.2\% in Ethiopia [90].

The severity of lesions among women with CIN grade 3 and ICC has been reported to be about $90 \%$ which is directly proportional to the prevalence of women with cytologic cervical pathology [87]. Prevalence of human immunodeficiency virus (HIV) in SSA is linked to several HPV-related cancers, supported by a cancer registry in Nigeria, which reported a two-fold increase of cervical cancers in people living with HIV (PLWH) [92]. A retrospective study by Oga and colleagues [93],demonstrated a minimal widespread presence of hr-HPV linked to head and neck cancers amongst Nigerians [93]. This current study based on this finding, observed that HPV attributable cervical cancer prevalence is increasing in SSA.

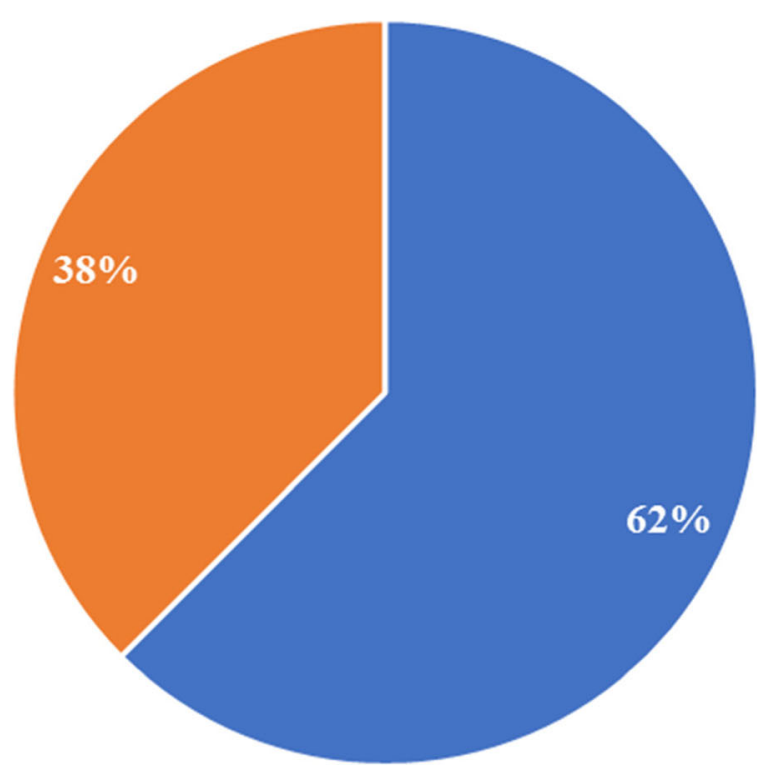

- Women

- Women and men

Fig. 2 Study population of the included studies 


\section{Incidence}

Seven of the included studies reported about the incidence of HPV-related cancers [10, 87-92]. Increased incidence rates of cervical cancer were noted in SSA in the entire world [10] and it ranks second after breast cancer in all SSA countries and its sub-regions [10]. Additionally, not less than four-fold higher incidence rates of cervical cancer are reported in LIC's countries predominantly SSA in comparison with very HIC's [87, 91]. According to Jedy et al., (2016) cervical cancer has shown to be commonly linked to HPV [92]. This was supported by similar incidence findings reported from West Africa at 29.3 per 100,000 and Central Africa at 28 per 100,000 and much higher occurrences reported in Southern Africa which amount to 38.2 per 100,000 and Eastern Africa that sum to 42.7 per 100,000 of cervical cancer incidence [92].

Worldwide, incidence rates of ICC were topmost at $>50 / 100,000$ women which are noted at the following countries; Malawi,Guinea, Tanzania, Zambia, and Mozambique [10]. Comparable results reported in a review by Louie et al., demonstrated an estimated overall age standardized incidence rate (ASR) of 31 per 100,000 women of ICC cases [90]. Global penile cancer incidence rates correlate with those of cervical cancer is estimated to be 26,300 cases annually [88]. The penile cancer incidence is noted to be higher in LMIC's, accounting to about $10 \%$ of penile cancers in certain regions of Africa [88].

Globally, an increasing incidence of anal cancer by $2 \%$ per year has been observed for the past three decades [92]. Annually, 27,000 new cases of anal cancer were diagnosed with an average worldwide incidence rate that sum to 1 per 100,000 [89]. However, in Uganda low occurrence rates of anal cancer have been reported at 0.2 per 100,000 in men and women and $<0.1$ per 100,000 in both Zimbabwean men and women [92]. Study performed in Nigeria, showed low incidence of oropharyngeal cancers attributable to HPV as low in Nigerian men and women [92]. There is rise in penile cancer incidence in some parts of Africa and low incidence rates of anal and oropharyngeal cancers observed in other countries within SSA.

\section{Mortality}

Three of the included studies reported about HPVrelated mortality $[10,87,91]$. Mortality rates is reported to be at least four-fold higher in LMICs mainly in SSA [87, 91]. Taking everything into account, within SSA the age-standardized incidence and mortality rates (ASIR and ASMR) of ICC are high at 31.7 and 22.5 per 100, 000 women with comparison to 9.1 and 3.1, respectively, in HICs [10]. In the SSA region, when estimated ICC is responsible for $1,474,208$ deaths in women aged 15 years or more [10]. Most of the studies showed that mortality in SSA due to HPV-related cancers is higher as compared to HICs.

\section{Trends}

Out of the eight included studies, about four of them reported about the trends of HPV-related cancers [10, 87, $89,92]$. Review by de Vuyst et al., demonstrated from selected registries trends of cervical cancer incidence has been observed [10]. The ten-year trends for Mali between 1987 and 1989 and 1994-1996 were increased from 23 to 36/100,000 over time, between 1991 and 1993 and 1998-2002 in Kyadondo, Uganda was 41 to 46/100,000 and between 1990 and 1992 and 1998-2002 in Zimbabwe a decrease was observed from 65 to $48 /$ 100,000 [10]. In the nineties, both Uganda and Zimbabwe experienced extremely elevated widespread presence of HIV among the general population, but opposite cervical cancer trends were showed over time, however with increased ASIR of 52/100,000 women for the period 2002-2006 [10]. In LMIC's there is limited information for trends of HPV linked oropharyngeal cancers [92], again possible underreporting for time trends for anogenital cancers is observed in LMIC's [89], associated with haphazard variations inherent to the small numbers involved $[87,89]$. The studies showed in SSA, time trends for cervical cancer is increasing and data on trends for other anogenital cancers is limited.

\section{Discussion}

This systematic scoping review provided evidencedbased knowledge on the prevalence, incidence, mortality and trends of cervical, anal, penile and head and neck cancers in SSA. The findings revealed a lack of research in different geographic locations and poor participation among men. Our results demonstrated that there is limited evidence on the recent studies that explores the prevalence, incidence, mortality and trends of HPVrelated cancers in SSA. Additionally, our results presented a scarcity of studies focusing on other HPVrelated cancers other than cervical cancer. In our observation, evidence of cervical cancer attributable to HPV dominates vaginal, anal, vulvar and head and neck cancers, the cancers are probably underreported as the evidence on their burden is limited. Unfortunately, data were insufficient for describing HPV-attributable vulvar or vaginal cancers. This study observation highlight a gap of knowledge on the epidemiological data on the recent HPV prevalence in SSA, which will have a potential impact in determining the distribution of $\mathrm{HPV}$ on different body sites (cervix, penis, vagina, vulva, anus and oropharynx).

This study revealed that incidence and mortality ratios of cervical cancer in SSA are higher than other parts of 
the world [10]. Similarly, the review by Arbyn et al., 2012 , in 2008 , mortality to incidence ratio amounted to $52 \%$ worldwide, with an estimation of 275,000 deaths of women from cervical cancer whereby approximately $88 \%$ occurred in LMICs [88]. This study shows low incidence rate of anal cancer reported among men and women in Uganda and Zimbabwe [92]. In contrast, a study which was conducted in the United States of America (USA) showed increase incidence rates of anal cancer in both males and females [94, 95]. This study also demonstrates low incidence of oropharyngeal cancer among Nigerians meanwhile study findings in the USA reported increased incidence rate of oropharyngeal cancer particularly, in men $[96,97]$. In this study, the penile cancer incidence is noted to be higher in LMICs, accounting for $10 \%$ of penile cancers in some parts of Africa [88]. Meanwhile an increasing incidence of vulvar, vaginal and penile cancers have been reported in Denmark [98] and Netherlands [99]. However, incidence rates for penile cancers and vaginal cancers have declined during the period 1973-2006 in the US [100, 101]. Worldwide, head and neck cancers are noted as the eighth most common cancer with approximately 650,000 new cases and 350,000 deaths reported each year [102]. According to GLOBOCAN 2012 report, worldwide Age Standardized Incidence Rate (ASR) of head and neck cancers were found to be 10.7 per 100, 000 in the United States and 9.0 per 100,000 population on the African continent [103].

All inclusive ASIR and ASMR of ICC are high in SSA amounting at 31.7 and 22.5 per 100,000 women as compared with 9.1 and 3.1, respectively, in more HICs [10], with less than two per 100,000 women reported in Western Europe, Australia and New Zealand [104]. This current study revealed an increase of cervical cancer ASIR between the period 2002-2006 [10], however this may be due to possible underreporting of time trends for anogenital cancers in LMICs [89]. Comparing with European cervical cancer in Scotland, the ASRs ranged from 7.7 to 11.8 per 100,000 women between the 5-year periods of 1972-1976 and 2007-2011 [105]. However, constant temporal rates of penile cancer are noted in Scotland and England [103]. There is declining trend of smoking associated with low incidence of head and neck squamous cell carcinoma in developing world [106]. However, there is limited data in Africa checking the review from cancer registry in SA, increase in oropharyngeal cancers among "coloured" South Africans from 1992 to 2001 was noted [106].

\section{Strengths and limitations of the study}

The methodology used in this study, systematic scoping reviews, allows for extensive literature search, with no date and language restriction. This study was also not limited to any age or population group. A systematic scoping review guided by Arksey and O'Malley's framework was used and it was the best method to map the evidence on cancers linked to HPV [20]. The PEO (population, exposure, and outcomes) framework was used during selection of studies as it was the appropriate heuristic to use based on the framed research question. Additionally, the results of the scoping review were presented following PRISMA recommendation, which ensured complete and transparent reporting. The MMAT tool version 2011 was used to assess the methodological quality and assess the risk of bias of the included studies.

We acknowledge the limitation in this scoping review. This systematic scoping study was limited to quantitative studies due to the use of PEO nomenclature. The exclusion of qualitative studies might have resulted in omission of some valuable data. Providing relevant solutions in this study has been a challenge as the literature of different cancer sites, especially for cancer of anal, vaginal, vulvar, and head and neck on this topic is limited. It is also possible that researches on the prevalence, incidence, mortality and trends of HPV-related cancer outcomes may exist under different terminologies not considered in this study. However, we included MeSH terms in the search to address this limitation.

\section{Implications for research}

This study shows limited recent evidence on the epidemiological data of HPV-related cancers especially on anal cancer across all genders, vaginal cancer, vulvar cancer, head and neck cancers and penile cancer. Additionally, we recommend more future studies to be conducted at different countries within SSA and in rural areas. It also calls for recruitment of more males to participate in research. Ongoing studies to explore the incidence, prevalence and mortality of these cancers by country and cancer sites in SSA are recommended. Trends in ASIR in SSA are not favorable, therefore more studies to determine the time trends of HPV-related cancers are required.

\section{Implication of practice}

This study revealed the need for policy makers in public health to take note on the prevalence of HPV in SSA, and development of HPV attributable cancers and to inform action or/and policies on preventing, diagnosing, and treating HPV-related conditions. The presence of low-cost technologies for testing HPV and inclusion of HPV vaccines should be made available in SSA. Better yet, after the first three-dose course of HPV vaccination in Rwanda has resulted in 93, 23\% coverage which showed good response [107], therefore other countries should be motivated to expand their vaccination 
programmes. Well recorded cancer registry data to assess the burden of non-cervical cancers is recommended.

\section{Conclusion}

This study enabled the authors to provide evidencedbased knowledge on the prevalence on the prevalence, incidence, mortality and trends of HPV associated cancers in countries within SSA. This review also highlighted a literature gap on recent epidemiological data on HPV prevalence in SSA, which may have a potential impact in determining the distribution of HPV on different body sites (cervix, penis, vagina, vulva, anus and oropharynx). Therefore, future research projects are recommended in SSA to enhance the value of data for consistent reporting on the epidemiology of HPV-related cancers.

\section{Abbreviations}

ASIR: Age-standardized incidence rate; ASMR: Age standardized mortality rate; ASR: Age-standardized incidence; HDI: Human development index; HIV: Human immune-deficiency virus; HPV: Human papilloma virus; HrHPV: High-risk human papilloma virus; IARC: International agency for research on cancer; ICC: Invasive cervical cancer; LMIC: Low-and-middle-income countries; MMAT: Mixed methods appraisal tool; PLHIV: People living with HIV; SSA: Sub-Saharan Africa; STI: Sexually transmitted infections; WHO: World Health Organization

\section{Acknowledgements}

We would like to thank the following institutions: College of Health Sciences and Library services at the University of KwaZulu-Natal for providing with resources to help us with setting up and conducting this research study.

\section{Availability of data materials}

The data reported and supporting this paper was sourced from the existing literature therefore are available through the detailed reference list.

\section{Author's contributions}

The study was conceptualized and designed by KMBL and TG. KMBL prepared the first draft of the study. KMBL and DK contributed in the abstract and full article screening of the studies. KMBL contributed on data extraction. TPM-T contributed in the synthesis of data and the design of the sifting and data extraction processes. DK and KMBL performed the methodology quality assessment of the included studies, data extraction, and contributed to the manuscript write up. TG, DK, and TPM-T critically reviewed the manuscript. All authors approved the final version of the manuscript.

\section{Funding}

University of KwaZulu-Natal, College of Health Sciences Research Scholarship funded this study.

\section{Ethics approval and consent to participate}

This paper is a scoping review, strictly relied on the review of existing literature. Since there were no animal or human participants in this study, ethical approval is not required.

\section{Consent for publication}

Not applicable.

\section{Competing interests}

All authors declared that they have no competing interest.
Received: 13 November 2018 Accepted: 31 May 2019

Published online: 11 June 2019

\section{References}

1. Stanley M, Lowy DR, Frazer I. Chapter 12: prophylactic HPV vaccines: underlying mechanisms. Vaccine. 2006;24(Suppl 3):S3/106-13.

2. Scheurer ME, Tortolero-Luna G, Adler-Storthz K. Human papillomavirus infection: biology, epidemiology, and prevention. Int J Gynecol Cancer. 2005;15(5):727-46.

3. Ghittoni R, Accardi R, Chiocca S, et al. Role of human papillomaviruses in carcinogenesis. E cancer medical science. 2015;9:526.

4. Subramanya D, Grivas PD. HPV and cervical cancer: updates on an established relationship. Postgrad Med. 2008;120(4):7-13.

5. Haedicke J, Iftner T. Human papillomaviruses and cancer. Radiother Oncol. 2013;108(3):397-402.

6. Bruni L, Diaz M, Castellsagué $X$, et al. Cervical human papillomavirus prevalence in 5 continents: meta-analysis of 1 million women with normal cytological findings. J Infect Dis. 2010;202(12):1789-99.

7. Bruni, L.; Barrionuevo-Rosas, L.; Albero, G.; Aldea, M.; Serrano, B.; Valencia, S., et al. Summary report 2016-02-26. Barcelona: ICO information Centre on HPV and Cancer; 2016. Human papillomavirus and related diseases in Senegal. Available from: http://www.hpvcentre.net/statistics/reports/SEN.pdf [Accessed 01 April 2016]

8. Centers for Disease, C. and Prevention. Human papillomavirus associated cancers-United States, 2004-2008. MMWR Morb Mortal Weekly Rep. 2012;61: 258-61.

9. Parkin DM. The global burden of infection-associated cancers in the year 2002. Int J Cancer. 2006;118(12):3030-44.

10. De Vuyst $H$, Alemany L, Lacey $C$, et al. The burden of human papillomavirus infections and related diseases in sub-Saharan Africa. Vaccine. 2013;31(Suppl 5):F32-46.

11. Ferlay J, Soerjomataram I, Dikshit R, et al. Cancer incidence and mortality worldwide: sources, methods and major patterns in GLOBOCAN 2012. Int J Cancer. 2015;136(5):E359-86.

12. World health Organization, 2015. Projections of mortality and causes of death, 2015 and 2030. (Last accessed October 2016). Available at: http:// www.who.int/healthinfo/global_burden_disease/projections/en/.

13. de Martel C, Ferlay J, Franceschi S, et al. Global burden of cancers attributable to infections in 2008: a review and synthetic analysis. Lancet Oncol. 2012;13:607-15.

14. Proceedings of the IARC Working Group on the Evaluation of Carcinogenic Risks to Humans. Biological Agents Lyon, France, 24 February-3 March 2009 IARC Monogr Eval Carcinog Risks Hum Vol 100B 2011. Available at: http://monographs.iarc.fr/ENG/Monographs/vol100B/ index.php. (last accessed July 2012).

15. Chaturvedi AK, Engels EA, Pfeiffer RM, et al. Human papillomavirus and rising oropharyngeal cancer incidence in the United States. J Clin Oncol 2011; 29(32):4294-4301. [PubMed Abstract].

16. Gillison ML, Chaturvedi AK, Lowy DR. HPV prophylactic vaccines and the potential prevention of noncervical cancers in both men and women. Cancer. 2008;113(10 Suppl):3036-46 [PubMed Abstract].

17. Gardasil [package insert]. Whitehouse Station. NJ: Merck \& Co., Inc.; 2009.

18. Cervarix [package insert]. Research Triangle Park. In: NC: Glaxo Smith-Kline; 2009.

19. Lekoane, et al. Mapping evidence on the burden of human papillomavirusrelated cancers in sub-Saharan Africa: scoping review protocol. Systematic Reviews. 2017;6:229. https://doi.org/10.1186/s13643-017-0623-3.

20. Arksey H, O'Malley L. Scoping studies: towards a methodological framework. Int J Soc Res Methodology. 2005;8(1):19-32.

21. Pluye $P$, et al. Proposal: a mixed methods appraisal tool for systematic mixed studies reviews. Montréal: McGill University; 2011. p. 1-8.

22. Adelstein DJ, Rodriguez CP. Human papillomavirus: changing paradigms in oropharyngeal cancer. Curr Oncol Rep. 2010;12(2):115-20.

23. Atlin CR, Chung J, Goldstein D, Johnson-Obaseki S, Bloom JA, Jaakkimainen $L$, et al. Assessing the need for an educational intervention for primary care practitioners on HPV-related oropharyngeal Cancer. Univ Tor Med J. 2016; 94(1):17-21

24. Auluck A, Hislop G, Bajdik C, Poh C, Lewei Z, Rosin M. Trends in oropharyngeal and Oral cavity Cancer incidence of human papillomavirus (HPV)-related and HPV-unrelated sites in a multicultural population. Cancer (0008543X). 2010;116(11):2635-44. 
25. Azvolinsky A. Concerned about HPV-related Cancer rise, researchers advocate boosting HPV vaccination rates. J Natl Cancer Inst. 2013;105(18):1335-6.

26. Barroca HM, Pontes P, Amendoeira IM. Anal HR-HPV prevalence assessed with the cobas $^{\circledR} \mathrm{HPV}$ test in an HIV-infected population of men who have sex with men. Porto Biomed J. 2016;1(1):29-31.

27. Barzon L, Cappellesso R, Peta E, Militello V, Sinigaglia A, Fassan M, et al. Profiling of expression of human papillomavirus-related cancer miRNAs in penile squamous cell carcinomas. Am J Pathol. 2014;184(12):3376-83.

28. Beachler DC, Weber KM, Margolick JB, Strickler HD, Cranston RD, Burk RD, Wiley DJ, Minkoff H, Reddy S, Stammer EE, Gillison ML. Risk factors for oral HPV infection among a high prevalence population of HIV-positive and at-risk HIVnegative adults. Cancer Epidemiol Prev Biomarkers. 2012;21(1):122-33.

29. Best SR, Niparko KJ, Pai SI. Biology of human papillomavirus infection and immune therapy for HPV-related head and neck cancers. Otolaryngol Clin N Am. 2012;45(4):807-22

30. Beachler DC, Abraham AG, Silverberg MJ, Jing Y, Fakhry C, Gill MJ, et al. Incidence and risk factors of HPV-related and HPV-unrelated head and neck squamous cell carcinoma in HIV-infected individuals. Oral Oncol. 2014;50(12):1169-76.

31. Biron VL, Cote DW, Seikaly H. Oropharyngeal squamous cell carcinoma and human papillomavirus-associated cancers in women: epidemiologic evaluation of association. J Otolaryngol Head Neck Surg. 2011;40(Suppl 1):S65-9.

32. Bodelon C, Untereiner ME, Machiela MJ, Vinokurova S, Wentzensen N. Genomic characterization of viral integration sites in HPV-related cancers. Int J Cancer. 2016;139(9):2001-11.

33. Borget I, Abramowitz L, Mathevet P. Economic burden of HPV-related cancers in France. Vaccine. 2011;29(32):5245-9.

34. Bosch F, Lorincz A, Munoz N, Meijer C, Shah K. The causal relation between human papillomavirus and cervical cancer. J Clin Pathol. 2002;55(4):244-65.

35. Chaturvedi AK. Beyond cervical cancer: burden of other HPV-related cancers among men and women. J Adolesc Health. 2010;46(4 Suppl):S20-6.

36. Chaturvedi AK, Engels EA, Anderson WF, Gillison ML. Incidence trends for human papillomavirus-related and-unrelated oral squamous cell carcinomas in the United States. J Clin Oncol. 2008;26(4):612-9.

37. Chaturvedi AK, Madeleine MM, Biggar RJ, Engels EA. Risk of human papillomavirus-associated cancers among persons with AIDS. J Natl Cancer Inst. 2009:101(16):1120-30.

38. L-m C, Rubin M, Smith-McCune K. Screening and treatment of HPV-related diseases in gynecologic practice. Seminars in Colon and Rectal Surgery. 2004;15(4):201-9.

39. Chow LT. Model systems to study the life cycle of human papillomaviruses and HPV-associated cancers. Virol Sin. 2015;30(2):92-100.

40. Clemente N, Alessandrini L, Vaccher E, De Paoli A, Buttignol M, Canzonieri V, et al. Multiple preinvasive and invasive HPV-related lesions of the anogenital tract in a female patient with HIV infection: A case report. Medicine. 2017; 96(4):e5948-e.

41. Conway EL, Farmer KC, Lynch WJ, Rees GL, Wain G, Adams J. Quality of life valuations of HPV-associated cancer health states by the general population. Sex Transm Infect. 2012;88(7):517-21.

42. Dillner J. Prevention of human papillomavirus-associated cancers. Semin Oncol. 2015;42(2):272-83.

43. D'souza G, Kreimer AR, Viscidi R, Pawlita M, Fakhry C, Koch WM, et al. Casecontrol study of human papillomavirus and oropharyngeal cancer. N Engl J Med. 2007;356(19):1944-56.

44. Dunne EF, Park IU. HPV and HPV-associated diseases. Infect Dis Clin N Am. 2013;27(4):765-78.

45. Joo Y-H, Lee Y-S, Cho K-J, Park J-O, Nam I-C, Kim C-S, et al. Characteristics and prognostic implications of high-risk HPV-associated Hypopharyngeal cancers. PLoS One. 2013;8(11):16.

46. Katz A. Ce: Human Papillomavirus-Related Oral Cancers: The Nurse's Role in Mitigating Stigma and Dispelling Myths. Am J Nurs. 2017;117(1):34-9.

47. Kreuter A, Wieland U. Human papillomavirus-associated diseases in HIVinfected men who have sex with men. Curr Opin Infect Dis. 2009;22(2): 109-14.

48. Krishnan A, Levine AM. Malignancies in women with HIV infection. Women's Health (Lond Engl). 2008;4(4):357-68.

49. Levovitz C, Chen D, Ivansson E, Gyllensten U, Finnigan JP, Alshawish S, et al. TGF-beta receptor 1: an immune susceptibility gene in HPV-associated cancer. Cancer Res. 2014;74(23):6833-44.

50. Liu C-Y, Li F, Zeng Y, M-Z T, Huang Y, Li J-T, et al. Infection and integration of high-risk human papillomavirus in HPV-associated cancer cells. Med Oncol. 2015;32(4):109.
51. Mayeaux EJ Jr. Reducing the economic burden of HPV-related diseases. J Am Osteopath Assoc. 2008;108(4):S2-7.

52. Meyer MF, Huebbers CU, Siefer OG, Vent J, Engbert I, Eslick GD, et al. Prevalence and risk factors for oral human papillomavirus infection in 129 women screened for cervical HPV infection. Oral Oncol. 2014;50(1):27-31.

53. Mirghani $H$, Sturgis EM, Aupérin A, Monsonego J, Blanchard P. Is there an increased risk of cancer among spouses of patients with an HPV-related cancer: a systematic review. Oral Oncol. 2017;67:138-45.

54. Nelson RA, Lai LL. Elevated risk of human papillomavirus-related second cancers in survivors of anal canal cancer. Cancer. 2017;123(20):4013-21.

55. Neumann F, Jégu J, Mougin C, Prétet J-L, Guizard A-V, Lapôtre-Ledoux B, et al. Risk of second primary cancer after a first potentially-human papillomavirusrelated cancer: a population-based study. Prev Med. 2016;90:52-8.

56. Nicol AF, Monsonego J, editors. Summary of the Eurogin 2011 conference: Highlighting the recent advances in HPV-related cancers.2011.

57. O'rorke M, Ellison M, Murray L, Moran M, James J, Anderson L. Human papillomavirus related head and neck cancer survival: a systematic review and meta-analysis. Oral Oncol. 2012;48(12):1191-201.

58. Ortiz AP, Perez-Irizarry J, Soto-Salgado M, Suarez E, Perez N, Cruz M, et al. Human papillomavirus-related cancers among people living with AIDS in Puerto Rico. Prev Chronic Dis. 2014;11:E80.

59. Paavonen J. Human papillomavirus infection and the development of cervical cancer and related genital neoplasia. Int J Infect Dis. 2007;11:S3-9.

60. Palefsky J. Human papillomavirus-related disease in people with HIV. Curr Opin HIV AIDS. 2009;4(1):52-6.

61. Palefsky JM. Cutaneous and genital HPV-associated lesions in HIV-infected patients. Clin Dermatol. 1997;15(3):439-47.

62. Palefsky JM. Human papillomavirus-associated anal and cervical cancers in HIV-infected individuals: incidence and prevention in the antiretroviral therapy era. Curr Opin HIV AIDS. 2017;12(1):26-30.

63. Schiech L. Hpv-related cancer: an equal opportunity danger. Nursing. 2010; 40(10):22-9.

64. Shack L, Lau HY, Longlong H, Doll C, Hao D. Trends in the incidence of human papillomavirus-related noncervical and cervical cancers in Alberta, Canada: a population-based study. CMAJ Open. 2014;2(3):E127-E32.

65. Stier EA, Sebring MC, Mendez AE, Ba FS, Trimble DD, Chiao EY. Prevalence of anal human papillomavirus infection and anal HPV-related disorders in women: a systematic review. Am J Obstet Gynecol. 2015;213(3):278-309.

66. Syrjänen S. Human papillomavirus infection and its association with HIV. Adv Dent Res. 2011;23(1):84-9.

67. Tornesello ML, Perri F, Buonaguro L, lonna F, Buonaguro FM, Caponigro F. HPV-related oropharyngeal cancers: from pathogenesis to new therapeutic approaches. Cancer Lett. 2014;351(2):198-205.

68. Van der Zee RP, Richel O, De Vries H, Prins JM. The increasing incidence of anal cancer: can it be explained by trends in risk groups. Neth J Med. 2013;71(8):401-11.

69. Vivenza D, Lo Nigro C, Denaro N, Fortunato M, Monteverde M, Tonissi F, et al. E1 detection as prognosticator in human papillomavirus-positive head and neck cancers. Int J Biol Markers. 2016;31(2):0.

70. Wagner S, Sharma SJ, Wuerdemann N, Knuth J, Reder H, Wittekindt C, et al. Human papillomavirus-related head and neck Cancer. Oncol Res Treat. 2017 40(6):334-40.

71. Wakeham K, Kavanagh K. The burden of HPV-associated anogenital cancers. Curr Oncol Rep. 2014;16(9):402.

72. Kahn JA, Burk RD, Squires KE, Kapogiannis BG, Rudy B, Xu J, et al. Prevalence and risk factors for HPV in HIV-positive young women receiving their first HPV vaccination. J Acquir Immune Defic Syndr. 2012;61(3):390-9.

73. Grulich $A E$, van Leeuwen MT, Falster MO, Vajdic CM. Incidence of cancers in people with HIV/AIDS compared with immunosuppressed transplant recipients: a meta-analysis. Lancet. 2007;370(9581):59-67.

74. Blomberg M, Nielsen A, Munk C, Kjaer SK. Trends in head and neck cancer incidence in Denmark, 1978-2007: focus on human papillomavirus associated sites. Int J Cancer. 2011;129(3):733-41.

75. Muñoz N, Bosch FX, de Sanjosé S, Herrero R, Castellsagué X, Shah KV, et al. Epidemiologic classification of human papillomavirus types associated with cervical cancer. N Engl J Med. 2003;2003(348):518-27.

76. Lowy R, Schiller JT. Reducing HPV-associated cancer globally. Cancer Prev Res (Phila). 2012;5(1):18-23.

77. Olesen TB, Iftner T, Mwaiselage J, Kahesa C, Rasch V, Ngoma T, et al. Prevalence and type distribution of human papillomavirus among 1813 men in Tanzania and the relationship to HIV status. Sex Transm Dis. 2013; 40(7):592-8 
78. Natunen K, Lehtinen J, Namujju P, Sellors J, Lehtinen M. Aspects of prophylactic vaccination against cervical cancer and other human papillomavirus-related cancers in developing countries. Infect Dis Obstet Gynecol. 2011;2011.

79. Gooi Z, Chan JY, Fakhry C. The epidemiology of the human papillomavirus related to oropharyngeal head and neck cancer. Laryngoscope. 2016;126(4): 894-900.

80. Carroll KA, Pierce J, Kovarik CL. Perianal Bowen disease in a child with human immunodeficiency virus. Pediatr Dermatol. 2010;27(2):166-9.

81. Brickman C, Palefsky JM. Human papillomavirus in the HIV-infected host: epidemiology and pathogenesis in the antiretroviral era. Curr HIV/AIDS Rep. 2015;12(1):6-15.

82. Firnhaber C, Wilkin T. Human papillomavirus vaccines: where do they fit in HIV-infected individuals? Current HIV/AIDS Reports. 2012;9(3):278-86.

83. Heard I. Human papillomavirus, cancer and vaccination. Cur Opin HIV AIDS 2011;6(4):297-302.

84. Palefsky J. Human papillomavirus-related tumors in HIV. Curr Opin Oncol. 2006;18(5):463-8.

85. Capo-chichi CD, Aguida B, Chabi NW, Acapko-Ezin J, Sossah-Hiffo J, Agossou VK, et al. Diversity of high-risk human papilloma viruses in women treated with antiretroviral and in healthy controls and discordance with cervical dysplasia in the south of Benin. Infect Agent Cancer. 2016;11:1-9.

86. Bosch FX, Manos MM, Muñoz N, Sherman M, Jansen AM, Peto J, et al. Prevalence of human papillomavirus in cervical cancer: a worldwide perspective. J Nat Cancer Inst. 1995;87(11):796-802.

87. Bosch FX, Broker TR, Forman D, Moscicki A-B, Gillison ML, Doorbar J, et al. Comprehensive control of human papillomavirus infections and related diseases. Vaccine. 2013:31:H1-H31.

88. Arbyn M, De Sanjosé S, Saraiya M, Sideri M, Palefsky J, Lacey C, et al. EUROGIN 2011 roadmap on prevention and treatment of HPV-related disease. Int J Cancer. 2012;131(9):1969-82.

89. De Sanjosé $\mathrm{S}$, Serrano B, Castellsagué X, Brotons M, Muñoz J, Bruni L, et al. Human papillomavirus (HPV) and related cancers in the Global Alliance for Vaccines and Immunization (GAVI) countries. A WHO/ICO HPV information Centre report. Vaccine. 2012;30(suppl(4):D1-D83.

90. Louie KS, De Sanjose S, Mayaud P. Epidemiology and prevention of human papillomavirus and cervical cancer in sub-Saharan Africa: a comprehensive review. Tropical Med Int Health. 2009;14(10):1287-302.

91. Forman D, de Martel C, Lacey CJ, Soerjomataram I, Lortet-Tieulent J, Bruni L, et al. Global burden of human papillomavirus and related diseases. Vaccine. 2012;30(Suppl 5):F12-23.

92. Jedy-Agba EE, Dareng EO, Adebamowo SN, Odutola M, Oga EA, Igbinoba F, et al. The burden of HPV associated cancers in two regions in Nigeria 20122014. Cancer Epidemiol. 2016:45:91-7

93. Oga EA, Schumaker LM, Alabi BS, Obaseki D, Umana A, Bassey I-A, et al. Paucity of HPV-related head and neck cancers (HNC) in Nigeria. PLoS One. 2016;11(4):1-9.

94. Johnson LG, Madeleine MM, Newcomer LM, Schwartz SM, Daling JR. Anal cancer incidence and survival: The surveillance, epidemiology, and end results experience, 1973-2000. Cancer. 2004;101:281-8.

95. Joseph DA, Miller JW, Wu X, et al. Understanding the burden of human papillomavirus-associated anal cancers in the US. Cancer. 2008;113(suppl 10):2892-900.

96. Brewster DH, Bhatti LA. Increasing incidence of squamous cell carcinoma of the anus in Scotland, 1975-2002. Br J Cancer. 2006;95:87-90.

97. FrischMet a. Trends in incidence of anal cancer in Denmark. BMJ. 1993;306: 419-22.

98. Baldur-Felskov B, Hannibal CG, Munk C, et al. Increased incidence of penile cancer and high-grade penile intraepithelial neoplasia in Denmark 19782008: a nationwide population-based study. Cancer Causes Control. 2012;23: 273-80 [PubMed]

99. Graafland NM, Verhoeven $\mathrm{RH}$, Coebergh JW, et al. Incidence trends and survival of penile squamous cell carcinoma in the Netherlands. Int J Cancer. 2011;128:426-32 [PubMed].

100. Barnholtz-Sloan JS, Maldonado JL, Pow-sang J, Giuliano AR. Incidence trends in primary malignant penile cancer. Urol Oncol. 2007;25:361-7.

101. Hernandez BY, Barnholtz-Sloan J, German RR, et al. Burden of penile cancer in the United States. Cancer. 2008;113(suppl(10):2883-91.

102. Ferlay J, Shin H-R, Bray F, Forman D, Mathers C, Parkin DM. Estimates of worldwide burden of cancer in 2008: GLOBOCAN 2008. Int J Cancer. 2010; 127(12):2893-917
103. Ferlay J, Soerjomataram I, Ervik M, Dikshit R, Eser S, Mathers C, et al. GLOBOCAN 2012 v1. 0, Cancer Incidence and Mortality Worldwide: IARC CancerBase No. 11. Lyon: International Agency for Research on Cancer; 2013. Visit: http://globocan.iarc.fr. 2014

104. International Agency for Research on Cancer. GLOBOCAN 2012. In: Cervical cancer estimated incidence, mortality and prevalence worldwide in 2012. http://globocan.iarc.fr/Pages/fact_sheets_cancer.aspx. Accessed 4 May 2014.

105. Information Service Division, Scotland. Cancer incidence and mortality in Scotland by site/type of cancer, sex and year of diagnosis/registration of death: 2002-2011. http://www.isdscotland.org

106. Marur S, D'Souza G, Westra WH, Forastiere AA. HPV-associated head and neck cancer: a virusrelated cancer epidemic. Lancet Oncol. 2010;11(August (8)):781-9 [PubMed: 20451455].

107. Ayo-Yusuf OA, Lalloo R, Johnson NW. Trends and ethnic disparities in oral and oro-pharyngeal cancers in South Africa, 1992-2001, SADJ 68 (may (4)); 2013. p. 168-73. [PubMed: 23971297]

\section{Publisher's Note}

Springer Nature remains neutral with regard to jurisdictional claims in published maps and institutional affiliations.
Ready to submit your research? Choose BMC and benefit from:

- fast, convenient online submission

- thorough peer review by experienced researchers in your field

- rapid publication on acceptance

- support for research data, including large and complex data types

- gold Open Access which fosters wider collaboration and increased citations

- maximum visibility for your research: over $100 \mathrm{M}$ website views per year

At BMC, research is always in progress.

Learn more biomedcentral.com/submissions 